Research Article

\title{
Behavior of Non-Digestible Polysaccharides in Gastrointestinal Tract: A Mechanistic Review of its Anti-Obesity Effect
}

\author{
Yajun Zhang ${ }^{1}$, Qingtong Xie ${ }^{1}$, Lijun You $^{1,2,}$, Peter Chi-Keung Cheung ${ }^{3}$, Zhengang Zhao ${ }^{1}$ \\ ${ }^{1}$ School of Food Science and Engineering, South China University of Technology, 381 Wushan Road, Guangzhou, Guangdong 510640, China \\ ${ }^{2}$ Overseas Expertise Introduction Center for Food Nutrition and Human Health (111 Center), Guangzhou, Guangdong 510640, China \\ ${ }^{3}$ Food and Nutritional Sciences, School of Life Sciences, The Chinese University of Hong Kong, Shatin, Hong Kong SAR, China
}

\section{ARTICLE INFO}

\section{Article History}

Received 18 January 2021

Accepted 10 March 2021

\section{Keywords}

Gastrointestinal tract

obesity

microbiota

non-digestible polysaccharides

digestion

fermentation

\section{ABSTRACT}

Nowadays, obesity in humans is a huge challenge requiring effective, readily available, and low-risk alternative treatments. Intake of edible Non-Digestible Polysaccharides (NDPs) is regarded as a promising strategy to combat obesity. Herein, an overview of the behavior of NDPs in the Gastrointestinal (GI) tract and its association with anti-obesity effect is summarized. Both the in vitro and in vivo of such investigations are discussed. Results show that NDPs can reach the large intestine to mediate the gut microbiota with the extent of regulation varies among NDPs with different chemical structures. The possible anti-obesity mechanisms associated with behavior of NDPs in the GI tract include: (i) inhibition of fat absorption, (ii) modification of gut microbiota and their metabolites such as short-chain fatty acids, (iii) regulation of bile acid profiles, (iv) modulation on appetite and satiety effect, and (v) protection of intestinal barrier. However, more efforts are required to clarify the exact behavior and their beneficial effects of NDPs within GI tract. This paper will provide an overlook of recent advances for better understanding anti-obesity activity of NDPs.

\section{HIGHLIGHTS}

- An overview of in vitro and in vivo studies on the behavior of edible Non-Digestible Polysaccharides (NDPs) in the Gastrointestinal (GI) tract is presented.

- The anti-obesity mechanisms of NDPs based on their GI behavior are discussed.

\section{GRAPHICAL ABSTRACT}

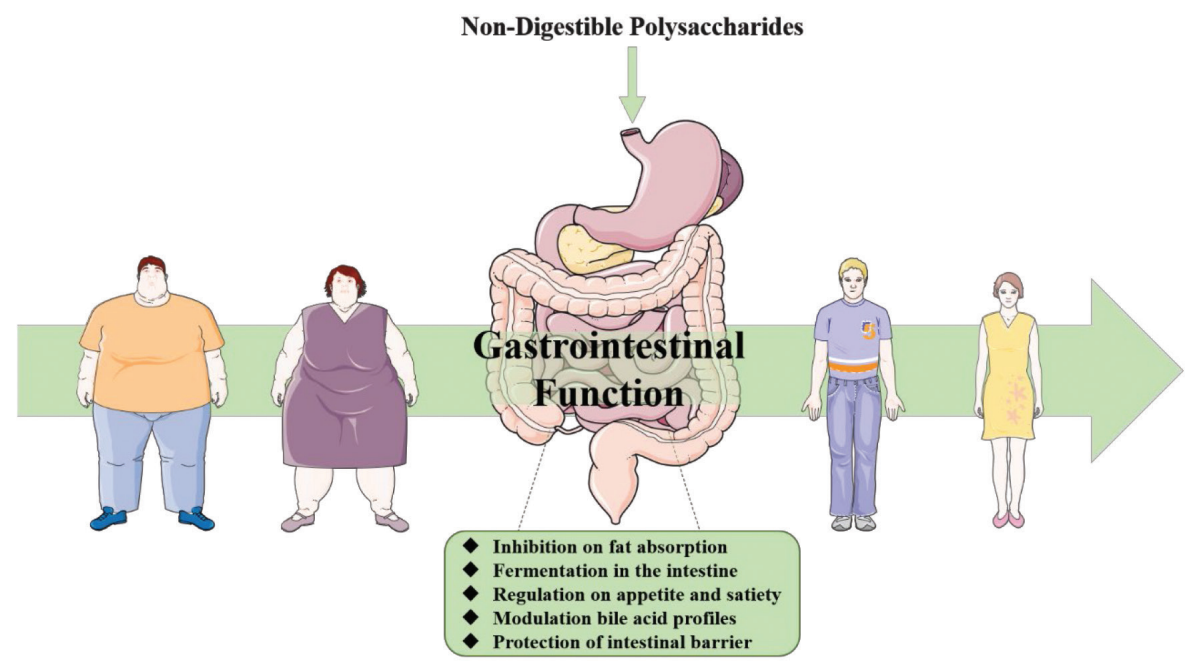

(C) 2021 The Authors. Publishing services by Atlantis Press International B.V. This is an open access article distributed under the CC BY-NC 4.0 license (http://creativecommons.org/licenses/by-nc/4.0/). 


\section{INTRODUCTION}

Today, obesity, an epidemic with excess or abnormal fat storage, has become a major concern for public health worldwide with rapidly expanding prevalence [1,2]. More than 650 million people are diagnosed with obesity in 2016 according to the World Health Organization [2] and 1 billion people will be influenced by 2030 [3]. Obesity and its multiple complications, such as hyperlipidemia, type 2 diabetes, certain cancers, and so on, all together contribute to reduced life quality, increased mortality, and huge medical expenses [4-6].

An energy imbalance arising from higher energy intake and lower energy expenditure is fundamentally responsible for the occurrence of obesity in addition to other involved factors including genetic metabolism, dysfunctional endocrine, and so on $[1,4,6]$. To date, strategies proposed to prevent obesity mainly contain anti-obesity drugs, bariatric surgery, diet, and exercise. Among these, the preferred method for fighting against obesity is to persist in regular exercise and a low-energy diet like controlling fat and sugar intake [7]. Nevertheless, the efficiency and success rate of this method has been questioned due to the difficulty of adhering [8]. Besides, anti-obesity drugs previously approved, such as orlistat, sibutramine, and rimonabant, have shown certain adverse effects [4]. Weight loss through gastric bypass or gastric band surgery is more effective than that of drug treatment [8]. However, only a few patients are suitable to adopt this treatment because of its higher risks and cost [4]. Accordingly, effective, readily available, as well as low-risk alternative therapies, have been being explored to treat or alleviate obesity in recent years [8].

As one of the natural products, Non-Digestible Polysaccharides (NDPs) have been in the spotlight of the studies concerning their effects on obesity (Figure 1). They are biomacromolecules composed of monosaccharides linked by glycosidic bonds, and widely distributed in plants, fungi, and microbes [3-9]. NDPs like konjac glucomannans [10], $\beta$-glucan [11] have been approved as food supplements for many years. Accumulating evidence has shown that they could prevent the development of obesity through a variety of mechanisms such as regulating lipids metabolism [12,13], reducing inflammation level [14-16], improving insulin resistance [17,18], and so on. The way that NDPs with relatively low bioavailability exert their anti-obesogenic activities in the body, such as changing the body composition, improving disordered metabolism are likely to be based on their behavior in the Gastrointestinal (GI) system to large extent. In this review, the behavior of edible NDPs in the GI

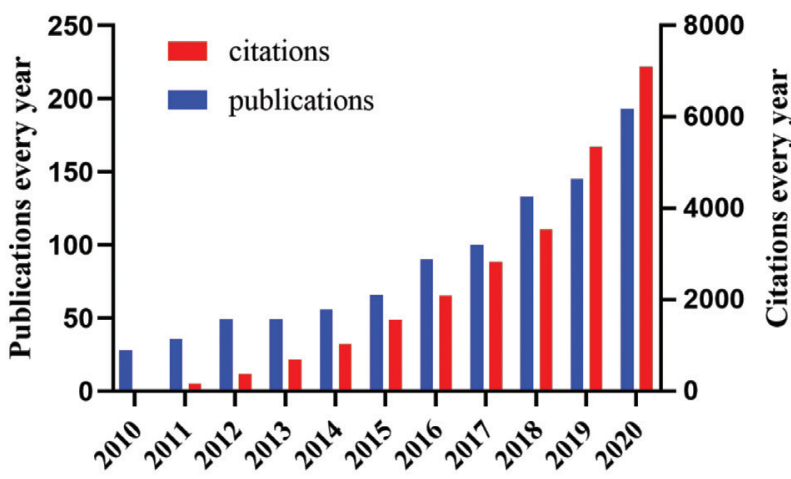

Figure 1 The trend of studies concerning polysaccharides and obesity in the past decade. The data was obtained from the website (http:// apps.webofknowledge.com). The theme was set as: "Polysaccharide and obesity". Retrieve date: February 2021. tract and their potential anti-obesity mechanisms associated with GI physiology are presented to provide some important insights for better understanding of their control of weight gain.

\section{OVERVIEW OF THE BEHAVIOR OF NDPS IN GI TRACT}

In recent years, the digestion and fermentation behavior of natural polysaccharides have been a hot topic for research. Researchers are increasingly interested in if polysaccharides are digestible, how they act on gut microbiota after oral administration, and in what form they are absorbed and functioned [19]. There are many methods proposed to study the changes of polysaccharides and the metabolites produced during the transit in GI tract, including in vitro and in vivo (animals or humans) models.

In terms of the study of digestion, due to the intricacy of our digestive system, in vivo digestive models adopt labeling techniques such as fluorescence labeling [19-21] or digesta collected from animals [22] to investigate the digestibility of polysaccharides. While, in vitro digestion models, either static or dynamic, commonly use digestive enzymes (e.g., salivary, pepsin, gastric lipase, pancreatin), bile salts, and electrolytes. And in vitro digestion models need to control parameters such as $\mathrm{pH}$, temperature, and digestion time to simulate physiological states of the upper GI tract, namely the oral, gastric, and intestinal phase (Figure 2). In contrast, in vivo digestion models are more ideal but are less used for studying digestion than in vitro digestion models owing to the technical difficulties, ethical limitations, and high costs [23]. Besides, there has been a rising interest in the characteristics of their fermentation of NDPs, such as the production of metabolites and alterations of chemical structure, and so on. The fermentation models are divided into in vivo, in vitro static, and in vitro dynamic models. The typical protocols of in vitro fermentation include collecting fresh feces from healthy volunteers without antibiotic treatment, preparing fecal inoculum, and then culturing under an anaerobic environment (Figure 2). Wang et al. [24] have recently reviewed the in vitro static and dynamic fermentation models including the simulator of the TNO in vitro model of the colon (TIM-2) and the human intestinal microbial ecosystem (SHIME ${ }^{\circledast}$.

In general, studies of digestive behavior of NDPs focus on changes in molecular weight and reducing sugar contents as well as fermentation by gut microbiota (Table 1). A few studies have also studied the changes in the conformation [25] and viscosity [26] of NDPs in

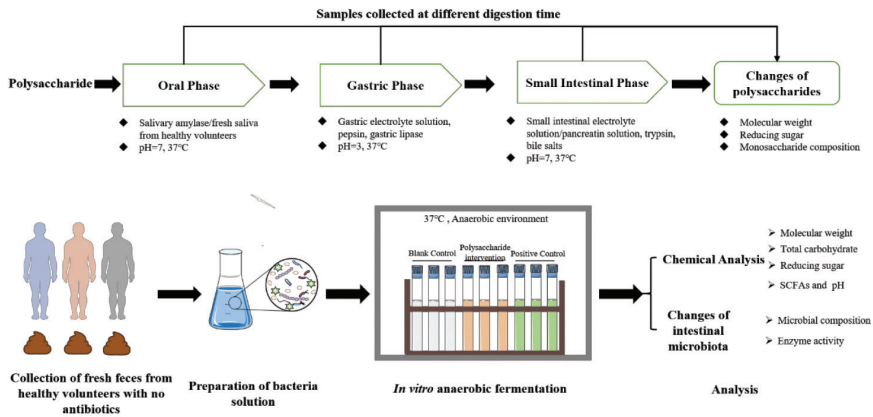

Figure 2 Typical protocols in investigating the digestive behaviors of NDPs in vitro. Images of Erlenmeyer flasks and tubes are referenced from the medical site http://smart.servier.com/ by Servier licensed under a Creative Commons Attribution 3.0 Unported License. 


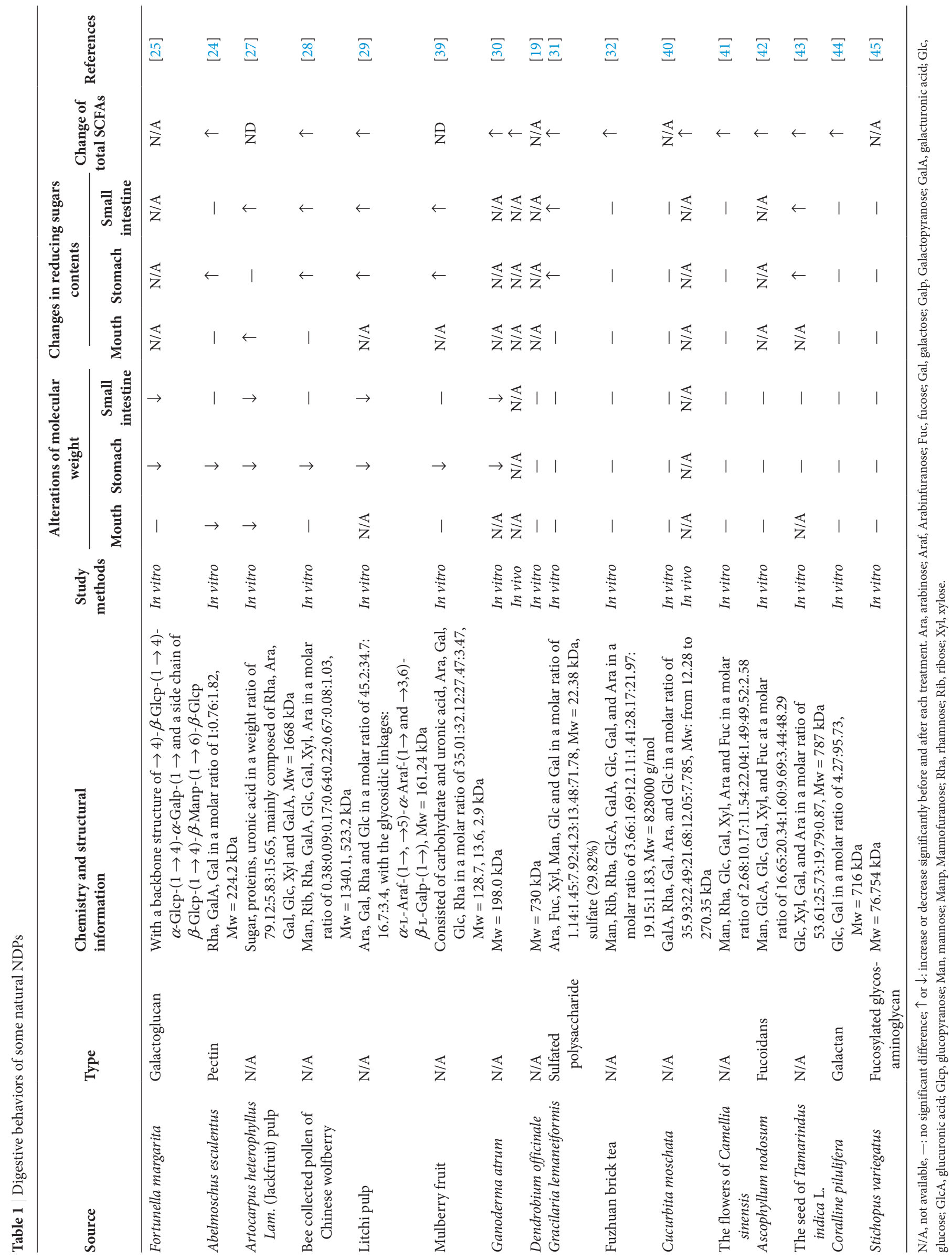


digestion. The experimental results generally varied with each polysaccharide on account of their unique chemical structure resulted from their sources or preparation methods. Some NDPs are partially degraded with a decrease in molecular weight and an increase in reducing sugar, which might be resulted from the effects of $\mathrm{pH}$, enzymes, and bile salts in the process of digestion [27-29]. Reasons for the decline in molecular weight of NDPs within GI tract include the disruption of aggregates and the hydrolysis of glycosidic bonds. However, most of them can resist the digestion of saliva, stomach, and small intestine and can be transited intact into the large intestine [30]. Recently, Li et al. [19] reported that polysaccharide from Dendrobium officinale kept intact during the upper GI tract both in vitro and in vivo, which was similar with many other polysaccharides [31-34]. In the large intestine, since the gut microbiota can generate a variety of carbohydrate-active enzymes [35], these NDPs or their corresponding digestive products (mono-/oligo-/ poly-saccharides) can be selectively utilized by gut microbiota to significantly decrease the $\mathrm{pH}$, increase the Short-Chain Fatty Acids (SCFAs), and modify the composition of gut microbiota. Such characteristics of the NDPs match with those criteria of prebiotics [36,37]. Furthermore, the health-promoting activities of polysaccharides are related to their fermentation by microbiota $[9,38]$. Nonetheless, the exact GI digestion behaviors, particularly the interactions between these polysaccharides or oligosaccharides and intestinal microbiota, still need further exploration. These above studies offer significant information for the diverse applications of polysaccharides in the food industry $[23,27,29,30]$.

\section{ANTI-OBESITY EFFECT VIA INHIBITING FAT ABSORPTION}

Obesity happens when energy expended is lower than that consumed. Therefore, it is an effective approach to fight against obesity by controlling the absorption of the energy-dense components in food, especially dietary fat [46]. Dietary fat mainly consists of mixed triglycerides [7]. Starting from the mouth, triglycerides are hydrolyzed, emulsified, and finally absorbed by the small intestine in the form of monoglycerides and free fatty acids [47]. Emerging studies have found that NDPs can significantly affect the process of fat digestion and absorption to prevent obesity via two principal targets, Pancreatic Lipase (PL) and Bile Acids (BAs) micelles.

Pancreatic lipase is a lipase secreted into the small intestine from the pancreas upon food intake [8]. It plays a predominant role in fat absorption in the GI tract, accounting for the hydrolysis of $50-70 \%$ of dietary fat [47]. Orlistat, one of the clinically approved antiobesity drugs, suppresses PL owing to the formation of covalent bonds with the catalytic sites of PL, thus reducing fat absorption $[4,8]$. But its side effects, such as bloating and diarrhea, can make patients feel uncomfortable [4]. Consequently, developing novel inhibitors from natural products of PL to treat obesity safely has attracted a lot of interest [48,49]. As reported, NDPs possessed inhibitory effects on PL to exert potentially anti-obesogenic effects both in vitro $[45,50,51]$ and in vivo $[5,52,53]$ (Table 2). Remarkably, the inhibitory effects of several NDPs are almost equal to that of orlistat. In a recent study, a barely $\beta$-glucan from black Qingke showed strong PL inhibitory effects $\left(\mathrm{IC}_{50}=2.315 \mathrm{mg} / \mathrm{mL}\right)$ in vitro, compared with orlistat $\left(\mathrm{IC}_{50}=2.051 \mathrm{mg} / \mathrm{mL}\right)$ [50]. Similarly, the excretion of fecal free fatty acids in High-Fat Diet (HFD) rats was elevated to
$21.39-35.86 \%$ by black tea polysaccharide extracts compared with orlistat [54]. This indicates that NDPs have the potential to be developed as an effective inhibitor of PL. Although plenty of polysaccharides with inhibitory effect on PL have been found, the precise relationships between structure and activity are not clear now. Currently, there are several probable structural factors concerning the inhibitory activity of polysaccharides on PL. On the one hand, it has been suggested that inhibitory effects on PL by polysaccharides might be attributed to several functional groups in the polysaccharides, including calcium ions [55], free carboxyl groups, sulfate groups, and so on. Zhao et al. [45] recently reported that the inhibitory effect on PL of a glycosaminoglycan was decreased significantly after desulfation or carboxyl reduction, which is similar with the result of desulfation of a galactofucan [56]. As anion groups, the sulfate groups and carboxyl groups might interact with PL via the formation of electrostatic interaction [45]. In addition, it was studied that inhibitory activities of polysaccharides on PL might be positively related to molecular weight and viscosity [50].

As a group of amphipathic steroid molecules synthesized from cholesterol by the liver, BAs are secreted into the small intestine to promote the digestion and absorption of foods including fat and cholesterol [8]. Previous studies have shown that polysaccharides binding with BAs could disrupt micelles where BAs act as emulsifiers, affecting the ability of micelle to solubilize the cholesterol, monoglycerides, and free fatty acids $[55,57,58]$. Subsequently, the absorption of fats and cholesterol within the small intestine can be reduced by polysaccharides, thus decreasing the risk of obesity and its complications [59]. However, despite the interest in the interactions between polysaccharides and BAs or BAs micelles, their nature remains unsure because of several restrictions such as in vivo intricate heterogeneity and limited access to samples, as well as the difficulty in simulating in vivo conditions in vitro [59]. To develop novel natural cholesterol-lowering agents, more efforts should be taken to uncover the mechanisms of actions of polysaccharides on BAs micelles in future studies.

\section{ANTI-OBESITY EFFECT VIA FERMENTATION IN THE INTESTINE}

As one of the most important prebiotics, NDPs may manipulate gut microbiota and their metabolites, such as SCFAs and secondary BAs, through their fermentation in the intestine to combat obesity and linked disorders (Table 3).

\subsection{Modification of Microbiota}

Over the past decade, the intestinal microbiota, a vital "microbial organ" composed of trillions of microbes [9], has caught widespread attention with the rapid development of associated sequencing technologies and omics technologies $[60,61]$. The casual relationship between obesity and intestinal microbiota has been discussed in many studies, among which a piece of evidence strongly shows that the intestinal microbiota from twins with different phenotype concerning obesity induces respective phenotypes in mice [62]. Recently, the intestinal microbiota is generally considered an environmental factor correlating the onset of obesity, although the underlying mechanisms are still not fully delineated $[1,63]$. 
Table 2 Inhibitory effects of lipase by NDPs

\begin{tabular}{|c|c|c|c|c|c|c|}
\hline Source & Name & Type & $\begin{array}{l}\text { Chemistry and structural } \\
\text { information }\end{array}$ & Methods & $\begin{array}{l}\text { Inhibitory effects } \\
\text { on lipase }\end{array}$ & References \\
\hline \multirow[t]{3}{*}{$\begin{array}{l}\text { Stichopus } \\
\text { variegatus }\end{array}$} & FG & \multirow[t]{3}{*}{ Glycosaminoglycan } & $\begin{array}{l}\text { With a } \beta 1,4 \text {-linked trisaccharide } \\
\text { repeating unit }-\left\{\left(\mathrm{L}_{-} \mathrm{Fuc}_{254 \mathrm{~s}}-\alpha 1,3-\right)\right. \\
\left.\mathrm{D}-\mathrm{GlcA}-\beta 1,3-\mathrm{D}-\mathrm{GalNAc}_{4865}\right\}- \\
\mathrm{Mw}=77 \mathrm{kDa}, \mathrm{GlcA}(19.62 \%, \\
\mathrm{w} / \mathrm{w}), \text { sulfate group }(35.83 \%, \mathrm{w} / \mathrm{w})\end{array}$ & In vitro & $\begin{array}{l}\text { Reducing PL activity by } \\
55.4 \% \text { at } 1.25 \mathrm{mg} / \mathrm{mL}\end{array}$ & \multirow[t]{3}{*}[45]{} \\
\hline & $\mathrm{dsFG}$ & & $\begin{array}{l}\text { The desulfated FG (the degree of } \\
\text { de-sulfation of dsFG }>91 \% \text { ) }\end{array}$ & In vitro & $\begin{array}{l}\text { Lower inhibitory activity } \\
\text { on PL compared with } \\
\text { FG }\end{array}$ & \\
\hline & crFG & & $\begin{array}{l}\text { The carboxyl-reduced FG (the } \\
\text { carboxyl groups were reduced } \\
\text { completely) }\end{array}$ & In vitro & $\begin{array}{l}\text { Lower inhibitory activity } \\
\text { on PL compared with } \\
\text { FG }\end{array}$ & \\
\hline \multirow[t]{2}{*}{ Laminaria japonica } & CGF-3 & \multirow[t]{2}{*}{ Galactofucan } & $\begin{array}{l}\text { Fuc, Xyl, Gal, Glc, GalA, } \\
\text { Man in a molar ratio of } \\
\text { 14.9:1.0:16.8:1.7:3.9:6.3, } \\
\text { Mw }=527.3 \mathrm{kDa} \text {, sulfate } \\
\text { groups }(26.7 \%)\end{array}$ & In vivo & $\begin{array}{l}\text { Decreasing PL activity to } \\
30.70 \% \text { at } 2.00 \mathrm{mg} / \mathrm{mL}\end{array}$ & \multirow[t]{2}{*}[56]{} \\
\hline & DSCGF-3 & & $\begin{array}{l}\text { The desulfated CGF-3 [sulfate } \\
\text { groups }(6.4 \%) \text { ] }\end{array}$ & In vitro & $\begin{array}{l}\text { Lower inhibitory activity } \\
\text { on PL compared with } \\
\text { CGF-3 }\end{array}$ & \\
\hline Ganyucang & ВТНВ & \multirow[t]{3}{*}{$\beta$-Glucan } & $\begin{array}{l}\text { Gal, Xyl, Ara, and Glc in a molar } \\
\text { ratio of } 0.42: 0.81: 1.0: 27.88 \\
\mathrm{Mw}=331.8 \mathrm{kDa}\end{array}$ & In vitro & $\mathrm{IC}_{50}=2.315 \mathrm{mg} / \mathrm{mL}$ & \multirow[t]{3}{*}[50]{} \\
\hline Dingqing & BLTHB & & $\begin{array}{l}\text { Gal, Xyl, Ara, and Glc in a molar } \\
\text { ratio of } 0.25: 0.74: 1.0: 24.05 \\
\mathrm{Mw}=196.3 \mathrm{kDa}\end{array}$ & In vitro & $\mathrm{IC}_{50}=3.712 \mathrm{mg} / \mathrm{mL}$ & \\
\hline Zangqing 320 & WTHB & & $\begin{array}{l}\text { Gal, Xyl, Ara, and Glc in a molar } \\
\text { ratio of } 0.26: 0.65: 1.0: 34.08 \\
\mathrm{Mw}=126.1 \mathrm{kDa}\end{array}$ & In vitro & $\mathrm{IC}_{50}=7.302 \mathrm{mg} / \mathrm{mL}$ & \\
\hline Codium fragile & CFSP & Sulfated polysaccharide & $\begin{array}{l}\text { Gal, Glc, Xyl in a molar ratio of } \\
\text { 79.82:18.24:1.94 }\end{array}$ & $\begin{array}{l}\text { In vitro } \\
\text { In vivo }\end{array}$ & $\begin{array}{l}\mathrm{IC}_{50}=101.81 \mu \mathrm{g} / \mathrm{mL} \\
\text { Reducing the lipase } \\
\text { activity in the intestine } \\
\text { by } 38 \% \text { after adminis- } \\
\text { tration at } 150 \mathrm{mg} / \mathrm{kg} \text { of } \\
\text { BW daily }\end{array}$ & {$[53]$} \\
\hline Cymodocea nodosa & CNSP & Sulfated polysaccharide & $\begin{array}{l}\text { Sugar, sulphate, proteins, lipids in a } \\
\text { weight ratio of 54.90:23.17:10.50:2.13 }\end{array}$ & $\begin{array}{l}\text { In vitro } \\
\text { In vivo }\end{array}$ & $\begin{array}{l}\mathrm{IC}_{50}=108.88 \mu \mathrm{g} / \mathrm{mL} \\
\text { Inhibiting the lipase } \\
\text { activity by } 30 \% \text { in the } \\
\text { intestine after interven- } \\
\text { tion with } 200 \mathrm{mg} / \mathrm{kg} \text { of } \\
\text { BW CNSP }\end{array}$ & [52] \\
\hline Cystoseira crinita & CCSP & Sulfated polysaccharide & $\begin{array}{l}\text { Ara, Man, All, Gal, Glc, GlcN, Alt, } \\
\text { Arap, Araf, Manf, Xylp, Galp, Galf, } \\
\text { Ribf in an area ratio of } 19: 6.9: 7.5: \\
\text { 8.98:0.4:1.02:7.1:0.5:0.5:1.8:1.6:6:0.3: } \\
\text { 0.08 by GC-MS analysis }\end{array}$ & $\begin{array}{l}\text { In vitro } \\
\text { In vivo }\end{array}$ & $\begin{array}{l}\mathrm{IC}_{50}=96.73 \mu \mathrm{g} / \mathrm{mL} \\
\text { Decreasing the intestinal } \\
\text { lipase activity by } 38 \% \\
\text { after oral intake at } \\
200 \mathrm{mg} / \mathrm{kg} \text { of BW daily }\end{array}$ & [5] \\
\hline
\end{tabular}

All, Allose; Alt, Altrose; Arap, Arabinopyranose; BLTHB, blue Qingke (Dingqing) $\beta$-glucan; BTHB, black Qingke (Ganyucang) $\beta$-glucan; CCSP, Cystoseira crinita sulfated polysaccharide; CFSP, sulphated polysaccharide from Codium fragile; CGF-3, a molecular-weight homogeneous fraction of polysaccharide from Laminaria japonica; CNSP, Cymodocea nodosa sulphated polysaccharide; crFG, carboxyl-reduced FG; DSCGF-3, desulfated CGF-3; dsFG, desulfated FG; FG, fucosylated glycosaminoglycan from sea cucumber; Galf, Galactofuranose; GalNAc, $\mathrm{N}$-acetyl-galactosamine; GC-MS, gas chromatography-mass spectrometry; GlcN, glucosamine; Ribf, ribofuranose; WTHB, white Qingke (Zangqing 320) $\beta$-glucan; Xylp, xylopyranose.

NDPs can combat obesity, specifically to enhance the diversity and richness of the microbiota, reduce the ratio between Firmicutes and Bacteroidetes (F/B), and alter specific genus- or species-level.

Mounting studies have found that the fermentation of several polysaccharides significantly increased microbial diversity and richness $[64,65]$. The diversity of intestinal microbiota in obese individuals has been reported to be lower than that of lean individuals [66]. There is evidence suggested that low richness of intestinal microbiota might be associated with reduced stability of the microbiota, resulted in elevated risk of obesity and its related metabolic disorders [67]. Thereby, a NDP-induced increase of microbial diversity or richness may be of great benefit to improve the dysfunctional microecology in the obese subjects.

In addition, an increase F/B correlates with enhanced capacity for energy absorption which ultimately resulted in obesity [68] Increased F/B in rodents [69] and humans [70] with obesity was 


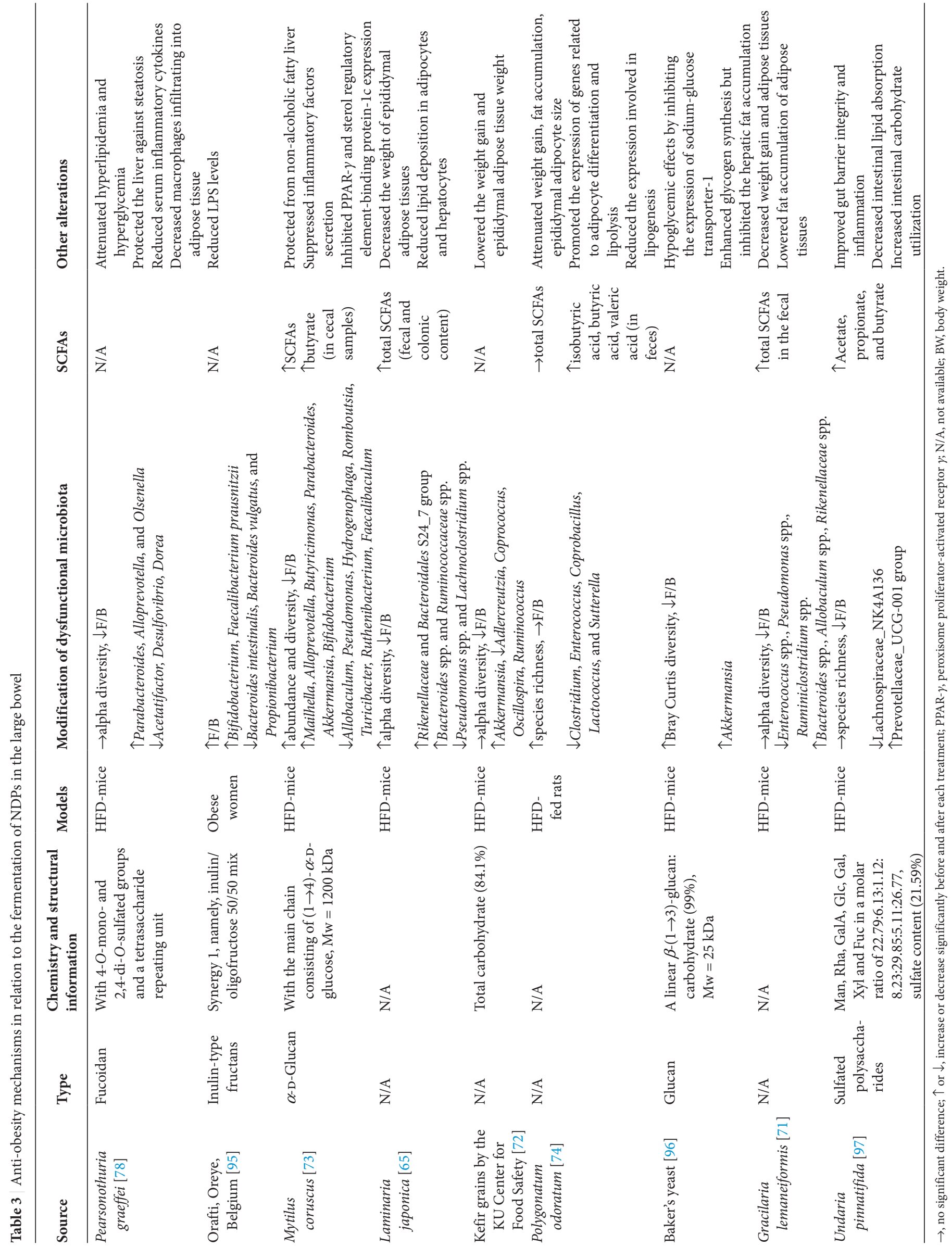


often observed, yet this variation can also be reversed by fermentation of many [71-73], but not all, polysaccharides [74,75]. Apart from these modifications, NDPs also lead to a decrease or increase in bacteria that are positively or negatively associated with obesity respectively through their fermentation in the intestine. For instance, NDP intervention by fucoidan could increase the beneficial bacterium Akkermansia muciniphila [76], which could ameliorate metabolic disorders in mice partly through up-regulating the intestinal levels of endocannabinoids in dietary obese mice [77]. Previous studies also observed some polysaccharides improved obesity along with an increased population of benign microbes such as Alloprevotella spp. [78], Prevotella spp. [79], Parabacteroides goldsteinii [80]. Likewise, it was demonstrated that a water extract of Ganoderma lucidum mycelium (WEGL) could prevent obesity via modifying the gut microbiota, therein including the reduction of Oscillibacter spp., Mucispirillum spp., and Eubacterium fergusonii [81]. These bacteria are in a positive association with inflammation and the development of obesity. And the high molecular weight polysaccharides $(>300 \mathrm{kDa})$ of WEGL was responsible for the anti-obesity activity of the extract [81].

Therefore, polysaccharides-induced alterations of gut microbiota might be of great significance to improve the dysfunctional intestinal microecology in the obese. However, it is noteworthy that the impacts on the gut microbiota of polysaccharides mentioned above might not be all present in a specific study. Meanwhile, further investigations should be paid to clarify the relationship between these impacts and anti-obesity activity by free-germ mice or fecal microbiota transplant studies $[80,81]$ to lay a foundation for targeting gut microbiota to treat obesity and related metabolic diseases using NDPs.

\subsection{SCFAs Production}

Anti-obesogenic activities of NDPs might be largely due to SCFAs generated during their fermentation. The SCFAs refer to a group of organic fatty acids with 2-6 carbon atoms including mainly acetate, propionate, and butyrate [82], which are involved in regulating physiological activities in local tissues. Firstly, enhanced SCFAs arising from NDP intake will directly lower the luminal $\mathrm{pH}$ values, suppressing the growth of pathogens [83]. Besides, SCFAs, particularly butyrate, have the capacity of supplying energy for the intestinal epithelial cells $[9,84]$, and participating in their regulation of proliferation and differentiation depending on concentration [9]. Several studies have elaborated on a protective role of SCFAs in maintaining the intestinal integrity [85-87], which is of great significance for health [88].

The local intestinal effects of SCFAs can determine which signals are subsequently triggered. For example, SCFAs activation of G-protein-coupled receptors GPR41 and GPR43 enhances the intestinal hormones Glucagon-like Peptide-1 (GLP-1) and Peptide YY (PYY) [89]. While these hormones locally regulate the motility of the gut [37], they subsequently enter circulation where they affect other organs to produce satiety, alleviate insulin resistance and inflammation in obese subjects [8].

Short-chain fatty acids can also affect distant organs/tissues (e.g., brain, liver, adipose tissue, and muscle) to exert their metabolic regulatory effects. Among them, adipose tissue is a major target. For example, SCFAs activated the GPR43 receptor in adipose tissue and inhibited the insulin signaling, which suppressed fat accumulation and promoted energy expenditure [90]. Also, acetate and propionate can be metabolized in the liver. Acetate serves as a lipogenic compound while propionate is one of the substrates for gluconeogenesis and can inhibit lipogenesis [83]. More recently, there are a lot of discussions concerning the effects of NDPs on the brain-gut axis [17], in which SCFAs might act as important mediators in interactions between the gut and brain. For example, acetate from colonic fermentation of NDP could cross the blood-brain barrier to directly decline appetite through a hypothalamic mechanism [91]. Above all, SCFAs not only influence the local tissues but serve as key metabolic signals to act on other tissues through a variety of pathways, thereby profoundly regulating metabolic activities. Increased SCFAs might be a key mediator in the impacts of fermentable NDPs.

In conclusion, the fermentation of NDPs in the intestine can be considered as an important target for control of weight gain, which is an outcome of a combination of multiple structural characteristics. NDPs with different molecular weight have different fermentation features. It was suggested that NDPs were more easily by intestinal microbiota when degraded or with appropriate molecular weight $[92,93]$. And the fermentation of pectin oligosaccharides was reported to be positively related to the branching degree and the content of neutral sugar [94]. Further works in structure-activity relationship should be paid more attention.

\section{ANTI-OBESITY VIA REGULATING APPETITE AND SATIETY}

Polysaccharides consumption can regulate appetite and satiety to manage food and energy intake, thereby preventing the development of obesity $[98,99]$. On the one hand, these effects depend in part on their physical effects like the bulking and viscosity effect as well as texture property [100]. The bulking effect does not only result in reduced food energy density and palatability but also contributes to satiety by inducing gastric distension [100]. Besides, some NDPs for example Konjac glucomannans [101] and increase the viscosity of digesta and slow the absorption of nutrients (especially fat which is discussed earlier), thus contributing to delayed gastric emptying, slowed bowel transit time, increased satiety, and reducing further food intake $[100,102]$.

On the other hand, food ingestion induces satiety in the GI tract through mechanical and humoral stimulation. NDPs can regulate the secretion of GI hormones such as GLP-1, PYY, Cholecystokinin (CCK) and ghrelin to control the uptake of food. A recent study found that a NDP from flaxseed contributed to satiety through up-regulation of GLP-1, which might further increase the level of adiponectin and promote lipid metabolism via AMP-Activated Protein Kinase (AMPK) regulation [13]. Several studies also have demonstrated that NDPs intake is positively associated with the level of PYY [103,104] and CCK [105]. CCK can inhibit the activity of hunger-stimulating neuropeptide $\mathrm{Y}$ in the hypothalamus [8]. However, some NDPs can decrease the expression of ghrelin that induces hunger via acting on hypothalamic brain cells in the central nervous system [106]. Fermentable NDPs produce SCFAs that are importantly involved in the regulation and control of appetite and satiety through stimulation of hormonal and neural signals in various organs and tissues [107]. 


\section{ANTI-OBESITY VIA REGULATING BA PROFILES}

Bile acids, consisting of primary and secondary BAs, play a pivotal role in the regulation of glycolipid metabolism in addition to assisting fats digestion and absorption. They are a group of vital signaling molecules with the ability to modulate energy metabolism by interacting with receptors, Takeda G protein Receptor 5 (TGR5), and Farnesoid X Receptor (FXR) [108,109]. Intestinal TGR5 could be activated by the secondary BAs, which induced GLP-1 secretion in intestinal L cells, alleviated glucose homeostasis, and combated obesity in obese mice [108]. And the inhibition of intestinal FXR could lower serum ceramides and promote beige fat thermogenesis, subsequently alleviating metabolic syndrome [109]. Moreover, the affinity and activation or inhibition potency on BA receptors vary with individual BAs [110]. As a result, BA profiles count to the energy regulation in the host and altered BA profiles have been investigated as a potential anti-obesity mechanism for NDPs.

Importantly, the BA profiles are closely linked to the intestinal microbiota. Bile Salt Hydrolase (BSH) enzymes secreted by some bacteria deconjugate conjugated primary BAs, thus generating unconjugated primary BAs. Unconjugated primary BAs escape uptake into the colon where they are dehydroxylated at $7 \alpha$ position to produce secondary BAs (deoxycholic and lithocholic acid) $[110,111]$. Other microbial modifications contain esterification, desulfation and so on [110]. Moreover, BSH activity was found to have significant effects on lipid metabolism, weight gain, and cholesterol levels in the host [111]. Gut microbiota dysbiosis and the decreased bacteria with BSH enzymes can result in perturbations of BA profiles and induce diseases related to glycolipid metabolism [112]. NDPs can target intestinal microbiota to regulate the BA profiles in the host. Chen et al. [113] observed that fucoidan could reverse the decreased $\mathrm{BSH}$ enzyme activity by modulating gut microbiota in HFD rats, modulate the BA composition, and finally improve the diet-induced dyslipidemia. Another study reported that intervention of a sulfated NDP could decrease the hydrophobic BAs but enhance the hydrophilic BAs might through up-regulating the relative abundance of Prevotellaceae_UCG-001, Corprococcus_1, and Alistipes and Roseburia and Lachnospiraceae_ NK4A136_group, respectively [114].

Furthermore, many polysaccharides can bind with BAs, which can suppress the enterohepatic circulation of BAs and affect BA pool size $[58,115,116]$. Specifically, the administration of a NDP from Ophiopogon japonicus (MDG-1) significantly decreased the serum total BAs levels as compared with the HFD group. Further detection of individual BAs in the urine, liver, and fecal suggested that MDG-1 could absorb BAs in the gut lumen, block the enterohepatic circulation and subsequently decrease the BA pool size in the liver. This inhibited the expression of FXR while activated the transcription of genes CYP7A1 and CYP8B1 involved in the synthesis of BAs in the liver, thus improving hyperlipidemia [117]. Meanwhile, polysaccharides with the capacity to bind with BAs likely provide a larger platform for BAs to interact with microbiota. Hence, the changes in gut microbiota resulting from a supplement of NDP significantly contribute to the BA profiles and metabolism of the host. Based on available evidence, we suggest a polysaccharide/gut microbiota/ BAs/FXR or TGR5 axis as a potential mechanism to understand anti-obesity activities of NDPs which still needs further research.

\section{ANTI-OBESITY VIA TARGETING INTESTINAL BARRIER FUNCTION}

An increase in serum Lipopolysaccharides (LPS) levels has been observed in subjects with diet-induced or genetic obesity $[95,118,119]$, which is called metabolic endotoxemia. It is a chronic condition where elevated LPS in serum can be recognized by Tolllike Receptor 4 (TLR4) on various tissues, subsequently bringing about systemic inflammation and insulin resistance $[83,119,120]$. There may be many potential causes of metabolic endotoxemia, one of which is that the disrupted intestinal barrier in the obese may allow the intestinal microbes and LPS to enter the circulation [121]. As shown in Table 4, polysaccharides in the intestine can improve the intestinal barrier to alleviate metabolic endotoxemia, hence exerting their anti-obesogenic effects.

An intact intestinal barrier is pivotal in separating the gut lumen from the inside of the body besides nutrition absorption. One of the key barriers is the intestinal mucous layer between enterocytes and the intestinal lumen. Generally, increasing the number of goblet cells and their expression of Mucin 2 (Muc2) is the target of certain polysaccharides to strengthen the mucous layer [122-124]. However, a recent study found that a NDP from apple counteracted the HFD-induced goblet cell hyperplasia and reduced thickness of the mucous layer by down-regulating Resistin-like Molecule $\beta(\operatorname{Re} \operatorname{lm} \beta)$ and promoting autophagic process rather than upregulating Muc2 expression [15].

Additionally, the tight junctions between two neighboring enterocytes act as a vital mechanical barrier closely linked with gut permeability and the translocation of toxins such as LPS [125]. They are composed of transmembrane tetraspan proteins (e.g., occludin, claudins), junctional adhesion molecules, and intracellular scaffold proteins (e.g., zonula occludens-1) [126]. It has been shown that obesity is characterized by increased permeability along with the decreased expression of tight junctions [80,127]. NDPs might promote tight junction related gene expression involving several specific pathways such as inhibition of nuclear factor kappa B/TLR4 [128] and up-regulation of AMPK [129], thus restoring the intestinal barrier and alleviating metabolic endotoxemia in obesity (Table 4). Moreover, as discussed earlier, the fermentation of certain NDPs in the gut lumen could regulate gut microbiota and yield of SCFAs, which may mediate the effect of polysaccharide on intestinal barrier since the alteration in commensal microbiota was reported to be related to metabolic endotoxemia and obesity $[120,121,130]$ and SCFAs can regulate intestinal integrity as mentioned earlier.

\section{CONCLUSION AND PERSPECTIVE}

In this review, we summarized the behavior of NDPs in the GI tract and highlighted their anti-obesity mechanisms in association with their physiological effects. Results show that NDPs can reach the colon, where they are utilized by colonic microbes. They show the therapeutic effects on obesity within the GI tract via mechanisms including controlling fat absorption, fermentation in the intestine, regulating BA profiles, appetite and satiety as well as improving metabolic endotoxemia by restoring the intestinal barrier (shown in Figure 3). Furthermore, these mechanisms are closely related to other metabolic impacts in the body. 
Table 4 NDPs that improve intestinal barrier and alleviate metabolic endotoxemia

\begin{tabular}{|c|c|c|c|c|c|c|c|}
\hline Source & Type & $\begin{array}{l}\text { Chemistry and structural } \\
\text { information }\end{array}$ & Models & $\begin{array}{l}\text { Daily intake } \\
\text { and period }\end{array}$ & $\begin{array}{l}\text { Impacts on the } \\
\text { intestinal barrier }\end{array}$ & Endotoxin & References \\
\hline Fuji apple & $\mathrm{N} / \mathrm{A}$ & $\begin{array}{l}\text { Rha, GalA, Glc, Gal and } \\
\text { Ara in a molar ratio of } \\
\text { 1.00:17.67:8.50:4.01:2.03, } \\
\mathrm{Mw}=2102.472,135.849 \\
9.622 \mathrm{kDa}\end{array}$ & HFD-rats & $\begin{array}{l}5 \%, 10 \%(\mathrm{w} / \mathrm{v}) \\
10 \mathrm{ml} / \mathrm{kg} \text { of } \mathrm{BW} \\
\text { for } 14 \text { weeks }\end{array}$ & $\begin{array}{l}\text { Decreased gut } \\
\text { permeability with } \\
\text { elevated expression } \\
\text { of occludin } \\
\text { Regulating the } \\
\text { function of goblet } \\
\text { cells through } \\
\text { inhibition of Relm } \beta \\
\text { and autophagy } \\
\text { induction }\end{array}$ & $\downarrow_{L B P}$ & {$[15]$} \\
\hline $\begin{array}{l}\text { Finger millet } \\
\text { CO (Ra) } 14\end{array}$ & Arabinoxylan & $\begin{array}{l}\text { Rha, Xyl, Man, Gal, Glc } \\
\text { in a molar ratio of } \\
\text { 35.3:44.7:3.7:9.5:6.8 }\end{array}$ & HFD-mice & $\begin{array}{l}1.0 \mathrm{~g} / \mathrm{kg} \text { of } \mathrm{BW} \text { on } \\
\text { every alternate day } \\
\text { for } 10 \text { weeks }\end{array}$ & $\begin{array}{l}\text { Improved colonic } \\
\text { barrier function } \\
\text { with up-regulation } \\
\text { of } \mathrm{ZO}-1 \text {, claudin } 2 \\
\text { and } 4, \text { Muc2 }\end{array}$ & $\downarrow_{\text {LPS }}$ & [127] \\
\hline Bamboo-shaving & Arabinoxylan & $\begin{array}{l}\text { With a main chain of } \beta-1,4- \\
\text { D-pyranoid xylose residues, } \\
\qquad \mathrm{Mw} \approx 10,000 \mathrm{~g} / \mathrm{mol}\end{array}$ & HFD-mice & $\begin{array}{l}400 \mathrm{mg} / \mathrm{kg} \text { of BW } \\
\text { for } 8 \text { weeks }\end{array}$ & $\begin{array}{l}\text { Improved intestinal } \\
\text { barrier integrity } \\
\text { as shown by the } \\
\text { complete structure } \\
\text { as well as clear } \\
\text { and inerratic tight } \\
\text { junction under the } \\
\text { transmission } \\
\text { electron } \\
\text { microscopy }\end{array}$ & $\downarrow$ LPS & {$[64]$} \\
\hline Hirsutella sinensis & $\mathrm{N} / \mathrm{A}$ & $\begin{array}{l}\text { A higher content of Man, } \\
\text { Gal, N-GalN, N-GlcN, } \\
\text { Rha and Fuc }\end{array}$ & HFD-mice & $\begin{array}{l}20 \mathrm{mg} / \mathrm{kg} \text { of BW } \\
\text { for } 12 \text { weeks }\end{array}$ & $\begin{array}{l}\text { Reduced intesti- } \\
\text { nal permeability } \\
\text { in HFD-fed } \\
\text { mice along with } \\
\text { enhanced } \\
\text { expression ZO-1 of } \\
\text { the colon }\end{array}$ & $\downarrow_{\text {LPS }}$ & {$[80]$} \\
\hline Poria cocos & $\beta$-glucan & $\begin{array}{l}1,3-\beta \text {-D-Glucan, } \\
\mathrm{Mw}=4.486 \times 10^{6} \mathrm{Da}\end{array}$ & $o b / o b$ mice & $\begin{array}{l}1 \mathrm{~g} / \mathrm{kg} \text { of BW for } \\
4 \text { weeks }\end{array}$ & $\begin{array}{l}\text { Maintained } \\
\text { intestinal integrity } \\
\text { by up-regulating } \\
\text { the expression of } \\
\text { Muc5, } \mathrm{ZO}-1 \text {, and } \\
\text { occludin in } \\
\text { the ileum }\end{array}$ & $\downarrow_{\text {LPS }}$ & [118] \\
\hline $\begin{array}{l}\text { Polygonatum } \\
\text { kingianum }\end{array}$ & N/A & $\begin{array}{c}\mathrm{Mw}=178.6 \mathrm{kDa} \text {, consists of } \\
\text { Man, GalA, Gal, and Fuc }\end{array}$ & HFD-rats & $\begin{array}{l}120 \mathrm{mg} / \mathrm{kg} \text { of BW } \\
\text { for } 14 \text { weeks }\end{array}$ & $\begin{array}{l}\text { Reversed the intestinal } \\
\text { barrier injuries by } \\
\text { elevating ZO-1 and } \\
\text { occludin expression }\end{array}$ & $\downarrow_{\text {LPS }}$ & {$[131]$} \\
\hline Apple & Pectin & $\mathrm{N} / \mathrm{A}$ & HFD-rats & $\begin{array}{l}\text { Free access to a } \\
\text { standard chow diet } \\
\text { with } 5 \% \text { pectin } \\
(\mathrm{w} / \mathrm{w}) \text { for } 6 \text { weeks }\end{array}$ & $\begin{array}{l}\text { Maintained gut } \\
\text { barrier function by } \\
\text { improving the level } \\
\text { of claudin } 1 \\
\text { Enhanced the expres- } \\
\text { sion of intestinal } \\
\text { alkaline phospha- } \\
\text { tase }\end{array}$ & $\downarrow_{\text {LPS }}$ & [132] \\
\hline Raphanus sativus & N/A & $\begin{array}{l}\text { Rha, Fuc, Ara, Xyl, Man, } \\
\text { Gal, Glc, GlcA and } \\
\text { GalA in molar ratios of } \\
5.4: 5.0: 22.9: 0.4 \\
\text { Mw }=61 \mathrm{kDa}\end{array}$ & HFD-mice & $\begin{array}{l}\text { HFD with a daily } \\
\text { oral gavage of } \\
2 \mathrm{mg} / \mathrm{kg} \text { for } \\
6 \text { weeks }\end{array}$ & $\begin{array}{l}\text { Improved gut bar- } \\
\text { rier function by } \\
\text { improving the level } \\
\text { of } \mathrm{ZO}-1 \\
\text { Restored colon } \\
\text { shortening }\end{array}$ & $\downarrow_{\text {LPS }}$ & [133] \\
\hline
\end{tabular}




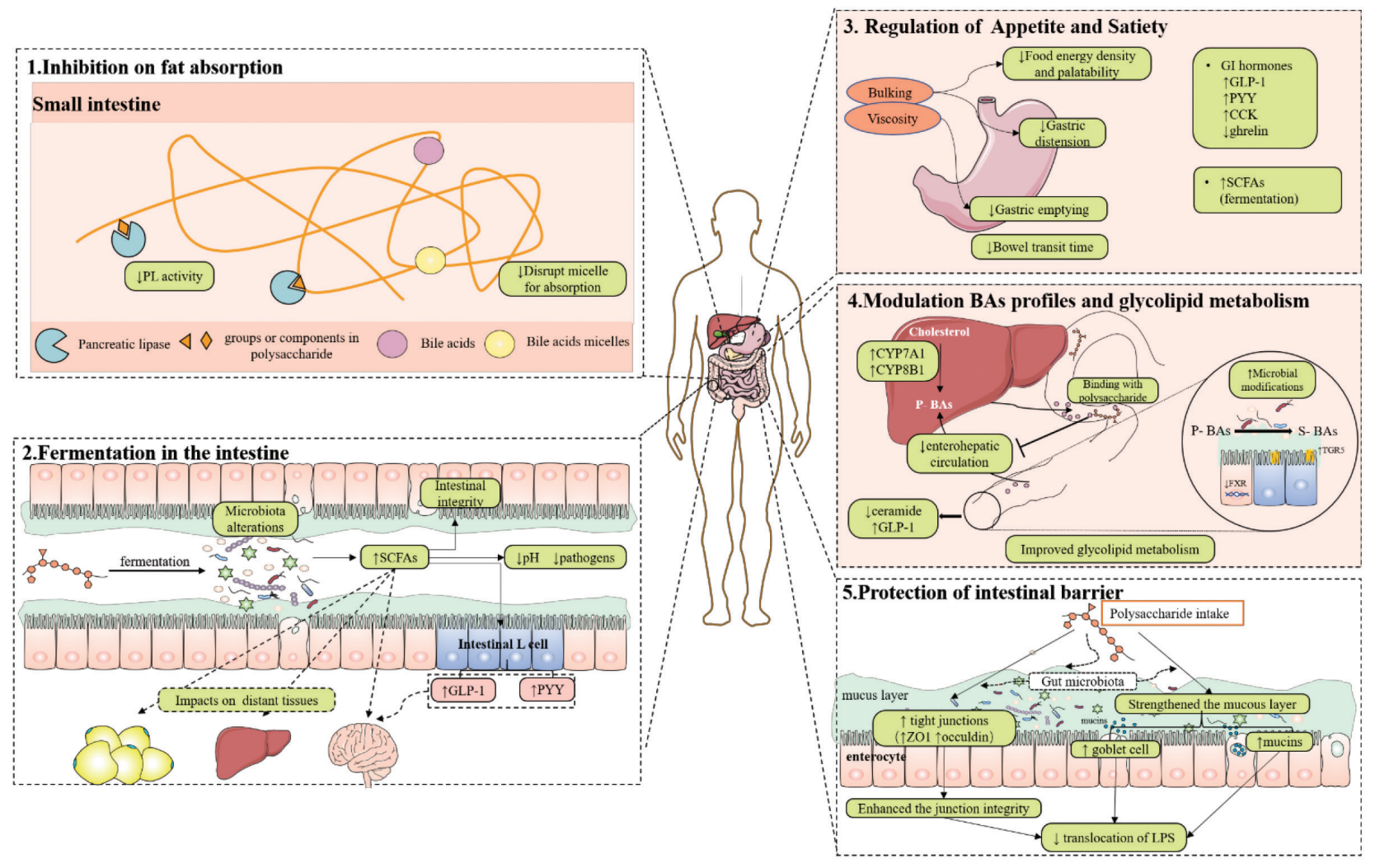

Figure 3 Schematic of mechanisms by which NDPs combat obesity during the gastrointestinal process. (1) NDPs regulate fat absorption via targeting the activity of PL and BAs micelles; (2) NDPs modify gut microbiota and SCFAs through fermentation in the intestine to exert their health-promoting activities; (3) NDPs enhance gastrointestinal satiety by their physical effects and gastrointestinal hormones formation to lower food intake; (4) NDPs regulate the BA profiles and glycolipid metabolism; (5) NDPs protect intestinal barrier and attenuate metabolic endotoxemia. P-BAs: primary BAs; S-BAs: secondary BAs. Images of GI tract and organs (brain, liver, stomach) are referenced from the medical site http://smart.servier.com/ by Servier licensed under a Creative Commons Attribution 3.0 Unported License.

In conclusion, the anti-obesogenic effects of NDPs during their GI digestion and fermentation are significant and worth further discussion. From Tables 2 to 4, anti-obesity effects and mechanisms of NDPs from different sources with structural and chemical composition differences are shown. At present, there is a lack of clear structureactivity relationships between NDPs and their anti-obesity effect, which should be further investigated. Furthermore, it is worth noting that there are still some factors to be considered for the practical application of NDPs in the prevention of obesity. For instance, how to solve the demand for fat-soluble nutrients when fat absorption is inhibited is worth considering. And the methods of NDPs preparation should be simpler, and economic for industrial production. Finally, consumption pattern [134] and dosage also influence the effectiveness of the NDPs. More toxicological studies are needed to find the optimal dose for clinical application. It is anticipated that new products based on NDPs for weight control after these problems are solved.

\section{CONFLICTS OF INTEREST}

The authors declare they have no conflicts of interest.

\section{AUTHORS' CONTRIBUTION}

$\mathrm{YZ}$ consulted the literature, drafted and revised the manuscript. QX, PC-KC and ZZ reviewed and edited the article. LY contributed in raising the idea, drafting the outline, revising, final approval and funding acquisition.

\section{ACKNOWLEDGMENTS}

The work was funded by the National Natural Science Foundation of China (31972011), the Guangzhou Science and Technology Program (201907010035), the Natural Science Foundation of Guangdong Province (2019A1515011670), the 111 project (B17018) and the Fundamental Research Funds for the Central Universities (2019MS101).

\section{REFERENCES}

[1] Sun L, Ma L, Ma Y, Zhang F, Zhao C, Nie Y. Insights into the role of gut microbiota in obesity: pathogenesis, mechanisms, and therapeutic perspectives. Protein Cell 2018;9:397-403.

[2] World Health Organization. Obesity. 2020. Available from: https://www.who.int/news-room/facts-in-pictures/detail/6facts-on-obesity.

[3] Zhang WL, Zhu L, Jiang JG. Active ingredients from natural botanicals in the treatment of obesity. Obes Rev 2014;15:957-67.

[4] González-Muniesa P, Mártinez-González MA, Hu FB, Després JP, Matsuzawa Y, Loos RJF, et al. Obesity. Nat Rev Dis Primers 2017;3:17034. 
[5] Ben Gara A, Ben Abdallah Kolsi R, Chaaben R, Hammami N, Kammoun M, Paolo Patti F, et al. Inhibition of key digestive enzymes related to hyperlipidemia and protection of liver-kidney functions by Cystoseira crinita sulphated polysaccharide in highfat diet-fed rats. Biomed Pharmacother 2017;85:517-26.

[6] Liang Y, Lin C, Huang S, Xu Y. Traditional Chinese medicine and intestinal microbiota: a complementary and integrative health approach to ameliorate obesity-related diseases. Holist Nurs Pract 2019;33:259-65.

[7] Chater PI, Wilcox MD, Houghton D, Pearson JP. The role of seaweed bioactives in the control of digestion: implications for obesity treatments. Food Funct 2015;6:3420-7.

[8] Martel J, Ojcius DM, Chang CJ, Lin CS, Lu CC, Ko YF, et al. Antiobesogenic and antidiabetic effects of plants and mushrooms. Nat Rev Endocrinol 2017;13:149-60.

[9] Zhang T, Yang Y, Liang Y, Jiao X, Zhao C. Beneficial effect of intestinal fermentation of natural polysaccharides. Nutrients 2018;10:1055.

[10] Shang W, Li H, Strappe P, Zhou Z, Blanchard C. Konjac glucomannans attenuate diet-induced fat accumulation on livers and its regulation pathway. J Funct Foods 2019;52:258-65.

[11] Joyce SA, Kamil A, Fleige L, Gahan CGM. The cholesterollowering effect of oats and oat beta glucan: modes of action and potential role of bile acids and the microbiome. Front Nutr 2019;6:171.

[12] Li L, Guo WL, Zhang W, Xu JX, Qian M, Bai WD, et al. Grifola frondosa polysaccharides ameliorate lipid metabolic disorders and gut microbiota dysbiosis in high-fat diet fed rats. Food Funct 2019;10:2560-72.

[13] Luo J, Qi J, Wang W, Luo Z, Liu L, Zhang G, et al. Antiobesity effect of flaxseed polysaccharide via inducing satiety due to leptin resistance removal and promoting lipid metabolism through the AMP-activated protein kinase (AMPK) signaling pathway. J Agric Food Chem 2019;67:7040-9.

[14] Sudirman S, Chang HW, Chen CK, Kong ZL. A dietary polysaccharide from Eucheuma cottonii downregulates proinflammatory cytokines and ameliorates osteoarthritis-associated cartilage degradation in obese rats. Food Funct 2019;10:5697-706.

[15] Wang S, Li Q, Zang Y, Zhao Y, Liu N, Wang Y, et al. Apple polysaccharide inhibits microbial dysbiosis and chronic inflammation and modulates gut permeability in HFD-fed rats. Int J Biol Macromol 2017;99:282-92.

[16] Kanwal S, Aliya S, Xin Y. Anti-obesity effect of Dictyophora indusiata mushroom polysaccharide (DIP) in high fat diet-induced obesity via regulating inflammatory cascades and intestinal microbiome. Front Endocrinol 2020;11:558874.

[17] Ahmadi S, Nagpal R, Wang S, Gagliano J, Kitzman DW, Soleimanian-Zad S, et al. Prebiotics from acorn and sago prevent high-fat-diet-induced insulin resistance via microbiomegut-brain axis modulation. J Nutr Biochem 2019;67:1-13.

[18] Zhang Y, Zuo J, Yan L, Cheng Y, Li Q, Wu S, et al. Sargassum fusiforme fucoidan alleviates high-fat diet-induced obesity and insulin resistance associated with the improvement of hepatic oxidative stress and gut microbiota profile. J Agric Food Chem 2020;68:10626-38.

[19] Li L, Yao H, Li X, Zhang Q, Wu X, Wong T, et al. Destiny of Dendrobium officinale polysaccharide after oral administration: indigestible and nonabsorbing, ends in modulating gut microbiota. J Agric Food Chem 2019;67:5968-77.

[20] Yu M, Xiao B, Hao X, Tan J, Gu J, Wang G, et al. Pumpkin polysaccharide preparation, simulated gastrointestinal digestion, and in vivo biodistribution. Int J Biol Macromol 2019;141: 1293-303.

[21] Wang K, Cheng F, Pan X, Zhou T, Liu X, Zheng Z, et al. Investigation of the transport and absorption of Angelica sinensis polysaccharide through gastrointestinal tract both in vitro and in vivo. Drug Deliv 2017;24:1360-71.

[22] Hasjim J, Lavau GC, Gidley MJ, Gilbert RG. In vivo and in vitro starch digestion: are current in vitro techniques adequate? Biomacromolecules 2010;11:3600-8.

[23] Minekus M, Alminger M, Alvito P, Ballance S, Bohn T, Bourlieu C, et al. A standardised static in vitro digestion method suitable for food - an international consensus. Food Funct 2014;5:1113-24.

[24] Wang M, Wichienchot S, He X, Fu X, Huang Q, Zhang B. In vitro colonic fermentation of dietary fibers: fermentation rate, shortchain fatty acid production and changes in microbiota. Trends Food Sci Technol 2019;88:1-9.

[25] Chen P, Lei S, Chen Y, Chang Q, Zhang Y, Hu X, et al. Structural characterization of a novel galactoglucan from Fortunella margarita and its molecular structural change following simulated digestion in vitro. J Funct Foods 2020;71:104024.

[26] Wu DT, Nie XR, Gan RY, Guo H, Fu Y, Yuan Q, et al. In vitro digestion and fecal fermentation behaviors of a pectic polysaccharide from okra (Abelmoschus esculentus) and its impacts on human gut microbiota. Food Hydrocolloid 2021;114:106577.

[27] Zhu K, Yao S, Zhang Y, Liu Q, Xu F, Wu G, et al. Effects of in vitro saliva, gastric and intestinal digestion on the chemical properties, antioxidant activity of polysaccharide from Artocarpus heterophyllus Lam. (Jackfruit) Pulp. Food Hydrocolloid 2019;87:952-9.

[28] Zhou W, Yan Y, Mi J, Zhang H, Lu L, Luo Q, et al. Simulated digestion and fermentation in vitro by human gut microbiota of polysaccharides from bee collected pollen of Chinese wolfberry. J Agric Food Chem 2018;66:898-907.

[29] Huang F, Liu Y, Zhang R, Bai Y, Dong L, Liu L, et al. Structural characterization and in vitro gastrointestinal digestion and fermentation of litchi polysaccharide. Int J Biol Macromol 2019;140:965-72.

[30] Ding Q, Nie S, Hu J, Zong X, Li Q, Xie M. In vitro and in vivo gastrointestinal digestion and fermentation of the polysaccharide from Ganoderma atrum. Food Hydrocolloid 2017;63:646-55.

[31] Han R, Pang D, Wen L, You L, Huang R, Kulikouskaya V. In vitro digestibility and prebiotic activities of a sulfated polysaccharide from Gracilaria Lemaneiformis. J Funct Foods 2020;64:103652.

[32] Chen G, Xie M, Wan P, Chen D, Ye H, Chen L, et al. Digestion under saliva, simulated gastric and small intestinal conditions and fermentation in vitro by human intestinal microbiota of polysaccharides from Fuzhuan brick tea. Food Chem 2018;244: 331-9.

[33] Di T, Chen G, Sun Y, Ou S, Zeng X, Ye H. In vitro digestion by saliva, simulated gastric and small intestinal juices and fermentation by human fecal microbiota of sulfated polysaccharides from Gracilaria rubra. J Funct Foods 2018;40:18-27.

[34] Bai J, Li T, Zhang W, Fan M, Qian H, Li Y, et al. Systematic assessment of oat $\beta$-glucan catabolism during in vitro digestion and fermentation. Food Chem 2021;348:129116.

[35] El Kaoutari A, Armougom F, Gordon JI, Raoult D, Henrissat B. The abundance and variety of carbohydrate-active enzymes in the human gut microbiota. Nat Rev Microbiol 2013;11:497-504.

[36] Ajanth Praveen M, Karthika Parvathy KR, Balasubramanian P, Jayabalan R. An overview of extraction and purification techniques of seaweed dietary fibers for immunomodulation on gut microbiota. Trends Food Sci Technol 2019;92:46-64. 
[37] Sanders ME, Merenstein DJ, Reid G, Gibson GR, Rastall RA. Probiotics and prebiotics in intestinal health and disease: from biology to the clinic. Nat Rev Gastroenterol Hepatol 2019;16: 605-16.

[38] Fang Q, Hu J, Nie Q, Nie S. Effects of polysaccharides on glycometabolism based on gut microbiota alteration. Trends Food Sci Technol 2019;92:65-70.

[39] Chen C, Zhang B, Fu X, You LJ, Abbasi AM, Liu RH. The digestibility of mulberry fruit polysaccharides and its impact on lipolysis under simulated saliva, gastric and intestinal conditions. Food Hydrocolloid 2016;58:171-8.

[40] Liang L, Liu G, Zhang F, Li Q, Linhardt RJ. Digestibility of squash polysaccharide under simulated salivary, gastric and intestinal conditions and its impact on short-chain fatty acid production in type-2 diabetic rats. Carbohydr Polym 2020;235:115904.

[41] Chen D, Chen G, Wan P, Hu B, Chen L, Ou S, et al. Digestion under saliva, simulated gastric and small intestinal conditions and fermentation in vitro of polysaccharides from the flowers of Camellia sinensis induced by human gut microbiota. Food Funct 2017;8:4619-29.

[42] Chen L, Xu W, Chen D, Chen G, Liu J, Zeng X, et al. Digestibility of sulfated polysaccharide from the brown seaweed Ascophyllum nodosum and its effect on the human gut microbiota in vitro. Int J Biol Macromol 2018;112:1055-61.

[43] Li X, Guo R, Wu X, Liu X, Ai L, Sheng Y, et al. Dynamic digestion of tamarind seed polysaccharide: indigestibility in gastrointestinal simulations and gut microbiota changes in vitro. Carbohydr Polym 2020;239:116194.

[44] Wang Y, Chen G, Peng Y, Rui Y, Zeng X, Ye H. Simulated digestion and fermentation in vitro with human gut microbiota of polysaccharides from Coralline pilulifera. LWT 2019;100:167-74.

[45] Zhao L, Qin Y, Guan R, Zheng W, Liu J, Zhao J. Digestibility of fucosylated glycosaminoglycan from sea cucumber and its effects on digestive enzymes under simulated salivary and gastrointestinal conditions. Carbohydr Polym 2018;186:217-25.

[46] Yue Y, Yadav SK, Wang C, Zhao Y, Zhang X, Wu Z. Nonabsorbable polysaccharide-functionalized polyethylenimine for inhibiting lipid absorption. Carbohydr Polym 2018;197:57-65.

[47] Birari RB, Bhutani KK. Pancreatic lipase inhibitors from natural sources: unexplored potential. Drug Discov Today 2007;12:879-89.

[48] Balasubramaniam V, Mustar S, Mustafa Khalid N, Abd Rashed A, Mohd Noh MF, Wilcox MD, et al. Inhibitory activities of three Malaysian edible seaweeds on lipase and $\alpha$-amylase. J Appl Phycol 2013;25:1405-12.

[49] BelHadj S, Hentati O, Elfeki A, Hamden K. Inhibitory activities of Ulva lactuca polysaccharides on digestive enzymes related to diabetes and obesity. Arch Physiol Biochem 2013;119:81-7.

[50] Guo H, Lin S, Lu M, Gong JDB, Wang L, Zhang Q, et al. Characterization, in vitro binding properties, and inhibitory activity on pancreatic lipase of $\beta$-glucans from different Qingke (Tibetan hulless barley) cultivars. Int J Biol Macromol 2018;120:2517-22.

[51] Zeng H, Miao S, Zhang Y, Lin S, Jian Y, Tian Y, et al. Isolation, preliminary structural characterization and hypolipidemic effect of polysaccharide fractions from Fortunella margarita (Lour.) Swingle. Food Hydrocolloid 2016;52:126-36.

[52] Ben Abdallah Kolsi R, Ben Gara A, Chaaben R, El Feki A, Patti FP, El Feki L, et al. Anti-obesity and lipid lowering effects of Cymodocea nodosa sulphated polysaccharide on high cholesterolfed-rats. Arch Physiol Biochem 2015;121:210-17.
[53] Kolsi RBA, Jardak N, Hajkacem F, Chaaben R, Jribi I, El Feki A, et al. Anti-obesity effect and protection of liver-kidney functions by Codium fragile sulphated polysaccharide on high fat diet induced obese rats. Int J Biol Macromol 2017;102:119-29.

[54] Wu T, Guo Y, Liu R, Wang K, Zhang M. Black tea polyphenols and polysaccharides improve body composition, increase fecal fatty acid, and regulate fat metabolism in high-fat diet-induced obese rats. Food Funct 2016;7:2469-78.

[55] Hu JL, Nie SP, Li C, Xie MY. In vitro effects of a novel polysaccharide from the seeds of Plantago asiatica L. on intestinal function. Int J Biol Macromol 2013;54:264-9.

[56] Zhang T, Wu S, Ai C, Wen C, Liu Z, Wang L, et al. Galactofucan from Laminaria japonica is not degraded by the human digestive system but inhibits pancreatic lipase and modifies the intestinal microbiota. Int J Biol Macromol 2021;166:611-20.

[57] Gao J, Lin L, Sun B, Zhao M. Comparison study on polysaccharide fractions from Laminaria japonica: structural characterization and bile acid binding capacity. J Agric Food Chem 2017;65:9790-8.

[58] Huang YL, Chow CJ, Tsai YH. Composition, characteristics, and in-vitro physiological effects of the water-soluble polysaccharides from Cassia seed. Food Chem 2012;134:1967-72.

[59] Gunness P, Gidley MJ. Mechanisms underlying the cholesterollowering properties of soluble dietary fibre polysaccharides. Food Funct 2010;1:149-55.

[60] Shang Q, Jiang H, Cai C, Hao J, Li G, Yu G. Gut microbiota fermentation of marine polysaccharides and its effects on intestinal ecology: an overview. Carbohydr Polym 2018;179:173-85.

[61] Tang C, Ding R, Sun J, Liu J, Kan J, Jin C. The impacts of natural polysaccharides on intestinal microbiota and immune responses - a review. Food Funct 2019;10:2290-312.

[62] Ridaura VK, Faith JJ, Rey FE, Cheng J, Duncan AE, Kau AL, et al. Gut microbiota from twins discordant for obesity modulate metabolism in mice. Science 2013;341:1241214.

[63] Cornejo-Pareja I, Muñoz-Garach A, Clemente-Postigo M, Tinahones FJ. Importance of gut microbiota in obesity. Eur J Clin Nutr 2019;72:26-37.

[64] Chen Y, Jin L, Li Y, Xia G, Chen C, Zhang Y. Bamboo-shaving polysaccharide protects against high-diet induced obesity and modulates the gut microbiota of mice. J Funct Foods 2018;49: $20-31$.

[65] Duan M, Sun X, Ma N, Liu Y, Luo T, Song S, et al. Polysaccharides from Laminaria japonica alleviated metabolic syndrome in $\mathrm{BALB} / \mathrm{c}$ mice by normalizing the gut microbiota. Int $\mathrm{J}$ Biol Macromol 2019;121:996-1004.

[66] Turnbaugh PJ, Hamady M, Yatsunenko T, Cantarel BL, Duncan A, Ley RE, et al. A core gut microbiome in obese and lean twins. Nature 2009;457:480-4.

[67] Le Chatelier E, Nielsen T, Qin J, Prifti E, Hildebrand F, Falony G, et al. Richness of human gut microbiome correlates with metabolic markers. Nature 2013;500:541-6.

[68] Turnbaugh PJ, Ley RE, Mahowald MA, Magrini V, Mardis ER, Gordon JI. An obesity-associated gut microbiome with increased capacity for energy harvest. Nature 2006;444:1027-31.

[69] Ley RE, Bäckhed F, Turnbaugh P, Lozupone CA, Knight RD, Gordon JI. Obesity alters gut microbial ecology. Proc Natl Acad Sci U S A 2005;102:11070-5.

[70] Ley RE, Turnbaugh PJ, Klein S, Gordon JI. Microbial ecology: human gut microbes associated with obesity. Nature 2006;444:1022-3. 
[71] Sun X, Duan M, Liu Y, Luo T, Ma N, Song S, et al. The beneficial effects of Gracilaria lemaneiformis polysaccharides on obesity and the gut microbiota in high fat diet-fed mice. J Funct Foods 2018;46:48-56.

[72] Lim J, Kale M, Kim DH, Kim HS, Chon JW, Seo KH, et al. Antiobesity effect of exopolysaccharides isolated from Kefir grains. J Agric Food Chem 2017;65:10011-19.

[73] Wu J, Shao H, Zhang J, Ying Y, Cheng Y, Zhao D, et al. Mussel polysaccharide $\alpha$-D-glucan (MP-A) protects against nonalcoholic fatty liver disease via maintaining the homeostasis of gut microbiota and regulating related gut-liver axis signaling pathways. Int J Biol Macromol 2019;130:68-78.

[74] Wang Y, Fei Y, Liu L, Xiao Y, Pang Y, Kang J, et al. Polygonatum odoratum polysaccharides modulate gut microbiota and mitigate experimentally induced obesity in rats. Int J Mol Sci 2018;19:3587.

[75] Chen G, Xie M, Wan P, Chen D, Dai Z, Ye H, et al. Fuzhuan brick tea polysaccharides attenuate metabolic syndrome in highfat diet induced mice in association with modulation in the gut microbiota. J Agric Food Chem 2018;66:2783-95.

[76] Shang Q, Song G, Zhang M, Shi J, Xu C, Hao J, et al. Dietary fucoidan improves metabolic syndrome in association with increased Akkermansia population in the gut microbiota of high-fat diet-fed mice. J Funct Foods 2017;28:138-46.

[77] Everard A, Belzer C, Geurts L, Ouwerkerk JP, Druart C, Bindels LB, et al. Cross-talk between Akkermansia muciniphila and intestinal epithelium controls diet-induced obesity. Proc Natl Acad Sci U S A 2013;110:9066-71.

[78] Li S, Li J, Mao G, Wu T, Hu Y, Ye X, et al. A fucoidan from sea cucumber Pearsonothuria graeffei with well-repeated structure alleviates gut microbiota dysbiosis and metabolic syndromes in HFD-fed mice. Food Funct 2018;9:5371-80.

[79] Kovatcheva-Datchary P, Nilsson A, Akrami R, Lee YS, De Vadder F, Arora T, et al. Dietary fiber-induced improvement in glucose metabolism is associated with increased abundance of prevotella. Cell Metab 2015;22:971-82.

[80] Wu TR, Lin CS, Chang CJ, Lin TL, Martel J, Ko YF, et al. Gut commensal Parabacteroides goldsteinii plays a predominant role in the anti-obesity effects of polysaccharides isolated from Hirsutella sinensis. Gut 2019;68:248-62.

[81] Chang CJ, Lin CS, Lu CC, Martel J, Ko YF, Ojcius DM, et al. Ganoderma lucidum reduces obesity in mice by modulating the composition of the gut microbiota. Nat Commun 2015;6:7489.

[82] Vallianou N, Stratigou T, Christodoulatos GS, Dalamaga M. Understanding the role of the gut microbiome and microbial metabolites in obesity and obesity-associated metabolic disorders: current evidence and perspectives. Curr Obes Rep 2019;8:317-32.

[83] Lin CS, Chang CJ, Lu CC, Martel J, Ojcius DM, Ko YF, et al. Impact of the gut microbiota, prebiotics, and probiotics on human health and disease. Biomed J 2014;37:259-68.

[84] Donohoe DR, Garge N, Zhang X, Sun W, O’Connell TM, Bunger $\mathrm{MK}$, et al. The microbiome and butyrate regulate energy metabolism and autophagy in the mammalian colon. Cell Metab 2011;13:517-26.

[85] Wang HB, Wang PY, Wang X, Wan YL, Liu YC. Butyrate enhances intestinal epithelial barrier function via up-regulation of tight junction protein claudin-1 transcription. Dig Dis Sci 2012;57:3126-35.

[86] Ferreira TM, Leonel AJ, Melo MA, Santos RRG, Cara DC, Cardoso VN, et al. Oral supplementation of butyrate reduces mucositis and intestinal permeability associated with 5-fluorouracil administration. Lipids 2012;47:669-78.

[87] Liu B, Qian J, Wang Q, Wang F, Ma Z, Qiao Y. Butyrate protects rat liver against total hepatic ischemia reperfusion injury with bowel congestion. PLoS One 2014;9:e106184.

[88] Vancamelbeke M, Vermeire S. The intestinal barrier: a fundamental role in health and disease. Expert Rev Gastroenterol Hepatol 2017;11:821-34.

[89] Liu Y, Chen J, Tan Q, Deng X, Tsai PJ, Chen PH, et al. Nondigestible oligosaccharides with anti-obesity effects. J Agric Food Chem 2020;68:4-16.

[90] Kimura I, Ozawa K, Inoue D, Imamura T, Kimura K, Maeda T, et al. The gut microbiota suppresses insulin-mediated fat accumulation via the short-chain fatty acid receptor GPR43. Nat Commun 2013;4:1829.

[91] Frost G, Sleeth ML, Sahuri-Arisoylu M, Lizarbe B, Cerdan S, Brody L, et al. The short-chain fatty acid acetate reduces appetite via a central homeostatic mechanism. Nat Commun 2014;5:3611.

[92] Yuan D, Li C, You L, Dong H, Fu X. Changes of digestive and fermentation properties of Sargassum pallidum polysaccharide after ultrasonic degradation and its impacts on gut microbiota. Int J Biol Macromol 2020;164:1443-50.

[93] Mao YH, Song AX, Li LQ, Yang Y, Yao ZP, Wu JY. A highmolecular weight exopolysaccharide from the Cs-HK1 fungus: ultrasonic degradation, characterization and in vitro fecal fermentation. Carbohydr Polym 2020;246:116636.

[94] Zhu R, Wang C, Zhang L, Wang Y, Chen G, Fan J, et al. Pectin oligosaccharides from fruit of Actinidia arguta: structureactivity relationship of prebiotic and antiglycation potentials. Carbohydr Polym 2019;217:90-7.

[95] Dewulf EM, Cani PD, Claus SP, Fuentes S, Puylaert PGB, Neyrinck AM, et al. Insight into the prebiotic concept: lessons from an exploratory, double blind intervention study with inulin-type fructans in obese women. Gut 2013;62:1112-21.

[96] Cao Y, Zou S, Xu H, Li M, Tong Z, Xu M, et al. Hypoglycemic activity of the Baker's yeast $\beta$-glucan in obese/type 2 diabetic mice and the underlying mechanism. Mol Nutr Food Res 2016;60:2678-90.

[97] Jiang P, Zheng W, Sun X, Jiang G, Wu S, Xu Y, et al. Sulfated polysaccharides from Undaria pinnatifida improved high fat diet-induced metabolic syndrome, gut microbiota dysbiosis and inflammation in BALB/c mice. Int J Biol Macromol 2021;167:1587-97.

[98] Egan ÁM, O’Doherty JV, Vigors S, Sweeney T. Prawn shell chitosan exhibits anti-obesogenic potential through alterations to appetite, affecting feeding behaviour and satiety signals in vivo. PLoS One 2016;11:e0149820.

[99] Georg Jensen M, Pedersen C, Kristensen M, Frost G, Astrup A. Review: efficacy of alginate supplementation in relation to appetite regulation and metabolic risk factors: evidence from animal and human studies. Obes Rev 2013;14:129-44.

[100] Burton-Freeman B. Dietary fiber and energy regulation. J Nutr 2000;130:272S-5S.

[101] Chua M, Baldwin TC, Hocking TJ, Chan K. Traditional uses and potential health benefits of Amorphophallus konjac K. Koch ex N.E.Br. J Ethnopharmacol 2010;128:268-78.

[102] Qi X, Al-Ghazzewi FH, Tester RF. Dietary fiber, gastric emptying, and carbohydrate digestion: a mini-review. Starch - Stärke 2018;70:1700346. 
[103] Keenan MJ, Zhou J, McCutcheon KL, Raggio AM, Bateman HG, Todd E, et al. Effects of resistant starch, a non-digestible fermentable fiber, on reducing body fat. Obesity (Silver Spring) 2006;14:1523-34.

[104] Adam CL, Thomson LM, Williams PA, Ross AW. Soluble fermentable dietary fibre (pectin) decreases caloric intake, adiposity and lipidaemia in high-fat diet-induced obese rats. PLoS One 2015;10:e0140392.

[105] Beck EJ, Tosh SM, Batterham MJ, Tapsell LC, Huang XF. Oat $\beta$-glucan increases postprandial cholecystokinin levels, decreases insulin response and extends subjective satiety in overweight subjects. Mol Nutr Food Res 2009;53:1343-51.

[106] Carvalho DV, Silva LMA, Alves Filho EG, Santos FA, de Lima RP, Viana AFSC, et al. Cashew apple fiber prevents high fat diet-induced obesity in mice: an NMR metabolomic evaluation. Food Funct 2019;10:1671-83.

[107] Chambers ES, Morrison DJ, Frost G. Control of appetite and energy intake by SCFA: what are the potential underlying mechanisms?. Proc Nutr Soc 2015;74:328-36.

[108] Thomas C, Gioiello A, Noriega L, Strehle A, Oury J, Rizzo G, et al. TGR5-mediated bile acid sensing controls glucose homeostasis. Cell Metab 2009;10:167-77.

[109] Jiang C, Xie C, Lv Y, Li J, Krausz KW, Shi J, et al. Intestineselective farnesoid $\mathrm{X}$ receptor inhibition improves obesityrelated metabolic dysfunction. Nat Commun 2015;6:10166.

[110] Long SL, Gahan CGM, Joyce SA. Interactions between gut bacteria and bile in health and disease. Mol Aspects Med 2017;56:54-65.

[111] Joyce SA, Macsharry J, Casey PG, Kinsella M, Murphy EF, Shanahan F, et al. Regulation of host weight gain and lipid metabolism by bacterial bile acid modification in the gut. Proc Natl Acad Sci U S A 2014;111:7421-6.

[112] Jones ML, Martoni CJ, Ganopolsky JG, Labbé A, Prakash S. The human microbiome and bile acid metabolism: dysbiosis, dysmetabolism, disease and intervention. Expert Opin Biol Ther 2014;14:467-82.

[113] Chen Q, Liu M, Zhang P, Fan S, Huang J, Yu S, et al. Fucoidan and galactooligosaccharides ameliorate high-fat diet-induced dyslipidemia in rats by modulating the gut microbiota and bile acid metabolism. Nutrition 2019;65:50-9.

[114] Huang S, Pang D, Li X, You L, Zhao Z, Cheung PCK, et al. A sulfated polysaccharide from Gracilaria Lemaneiformis regulates cholesterol and bile acid metabolism in high-fat diet mice. Food Funct 2019;10:3224-36.

[115] Palanisamy M, Aldars-García L, Gil-Ramírez A, Ruiz-Rodríguez A, Marín FR, Reglero G, et al. Pressurized water extraction of $\beta$-glucan enriched fractions with bile acids-binding capacities obtained from edible mushrooms. Biotechnol Prog 2014;30:391-400.

[116] Deng W, Yang X, Zhu Y, Yu J, Xu X. Structural characterization and hypolipidemic activities of purified stigma maydis polysaccharides. Food Sci Nutr 2019;7:2674-83.

[117] Shi L, Wang J, Wang Y, Feng Y. MDG-1, an Ophiopogon polysaccharide, alleviates hyperlipidemia in mice based on metabolic profile of bile acids. Carbohydr Polym 2016;150:74-81.

[118] Sun SS, Wang K, Ma K, Bao L, Liu HW. An insoluble polysaccharide from the sclerotium of Poria cocos improves hyperglycemia, hyperlipidemia and hepatic steatosis in $o b / o b$ mice via modulation of gut microbiota. Chin J Nat Med 2019;17:3-14.
[119] Cani PD, Amar J, Iglesias MA, Poggi M, Knauf C, Bastelica D, et al. Metabolic endotoxemia initiates obesity and insulin resistance. Diabetes 2007;56:1761-72.

[120] Cani PD, Bibiloni R, Knauf C, Waget A, Neyrinck AM, Delzenne $\mathrm{NM}$, et al. Changes in gut microbiota control metabolic endotoxemia-induced inflammation in high-fat diet-induced obesity and diabetes in mice. Diabetes 2008;57:1470-81.

[121] Rastelli M, Knauf C, Cani PD. Gut microbes and health: a focus on the mechanisms linking microbes, obesity, and related disorders. Obesity (Silver Spring) 2018;26:792-800.

[122] Tanabe H, Sugiyama K, Matsuda T, Kiriyama S, Morita T. Small intestinal mucins are secreted in proportion to the settling volume in water of dietary indigestible components in rats. J Nutr 2005;135:2431-7.

[123] Hino S, Takemura N, Sonoyama K, Morita A, Kawagishi H, Aoe S, et al. Small intestinal goblet cell proliferation induced by ingestion of soluble and insoluble dietary fiber is characterized by an increase in sialylated mucins in rats. J Nutr 2012;142:1429-36.

[124] Maria-Ferreira D, Nascimento AM, Cipriani TR, Santana-Filho AP, da Silva Watanabe P, de Mello Gonçales Sant Ana D, et al. Rhamnogalacturonan, a chemically-defined polysaccharide, improves intestinal barrier function in DSS-induced colitis in mice and human Caco-2 cells. Sci Rep 2018;8:12261.

[125] Barlow GM, Yu A, Mathur R. Role of the gut microbiome in obesity and diabetes mellitus. Nutr Clin Pract 2015;30:787-97.

[126] Bernardi S, Del Bo C, Marino M, Gargari G, Cherubini A, Andrés-Lacueva C, et al. Polyphenols and intestinal permeability: rationale and future perspectives. J Agric Food Chem 2020;68:1816-29.

[127] Sarma SM, Singh DP, Singh P, Khare P, Mangal P, Singh S, et al. Finger millet arabinoxylan protects mice from high-fat diet induced lipid derangements, inflammation, endotoxemia and gut bacterial dysbiosis. Int J Biol Macromol 2018;106:994-1003.

[128] Han J, Liu L, Yu N, Chen J, Liu B, Yang D, et al. Polysaccharides from Acanthopanax senticosus enhances intestinal integrity through inhibiting TLR4/NF- $\mathrm{B}$ signaling pathways in lipopolysaccharide-challenged mice. Anim Sci J 2016;87:1011-8.

[129] Yue Y, Wu S, Li Z, Li J, Li X, Xiang J, et al. Wild jujube polysaccharides protect against experimental inflammatory bowel disease by enabling enhanced intestinal barrier function. Food Funct 2015;6:2568-77.

[130] Boutagy NE, Mcmillan RP, Frisard MI, Hulver MW. Metabolic endotoxemia with obesity: is it real and is it relevant?. Biochimie 2016;124:11-20.

[131] Gu W, Wang Y, Zeng L, Dong J, Bi Q, Yang X, et al. Polysaccharides from Polygonatum kingianum improve glucose and lipid metabolism in rats fed a high fat diet. Biomed Pharmacother 2020;125:109910.

[132] Jiang T, Gao X, Wu C, Tian F, Lei Q, Bi J, et al. Apple-derived pectin modulates gut microbiota, improves gut barrier function, and attenuates metabolic endotoxemia in rats with dietinduced obesity. Nutrients 2016;8:126.

[133] Do MH, Lee HB, Oh MJ, Jhun H, Choi SY, Park HY. Polysaccharide fraction from greens of Raphanus sativus alleviates high fat diet-induced obesity. Food Chem 2021;343:128395.

[134] Liu Y, Ma N, Sun X, Duan M, Luo T, Jiang P, et al. Effect of intake pattern of sulfated polysaccharides on its biological activity in high fat diet-fed mice. Int J Biol Macromol 2019;132:9-16. 